This item was submitted to Loughborough's Research Repository by the author.

Items in Figshare are protected by copyright, with all rights reserved, unless otherwise indicated.

\title{
Water quality management for domestic rainwater harvesting systems in Fiji
}

PLEASE CITE THE PUBLISHED VERSION

http://dx.doi.org/10.2166/ws.2014.93

\section{PUBLISHER}

(C) IWA Publishing

\section{VERSION}

AM (Accepted Manuscript)

\section{PUBLISHER STATEMENT}

This work is made available according to the conditions of the Creative Commons Attribution-NonCommercialNoDerivatives 4.0 International (CC BY-NC-ND 4.0) licence. Full details of this licence are available at: https://creativecommons.org/licenses/by-nc-nd/4.0/

\section{LICENCE}

CC BY-NC-ND 4.0

\section{REPOSITORY RECORD}

Kohlitz, J.P., and Michael D. Smith. 2019. "Water Quality Management for Domestic Rainwater Harvesting Systems in Fiji”. figshare. https://hdl.handle.net/2134/17378. 
Word Count: 4,985

WATER QUALITY MANAGEMENT FOR DOMESTIC

RAINWATER HARVESTING SYSTEMS IN FIJI

Kohlitz, J.P. ${ }^{1}$ and Smith, M.D. ${ }^{2}$

${ }^{1}$ Corresponding author, 3546 Natural Ln, Jackson, MI 49203 USA, jkohlitz@gmail.com

${ }^{2}$ Water, Engineering and Development Centre (WEDC), The John Pickford Building,

Loughborough University, Leicestershire LE11 3TU, UK 


\begin{abstract}
Health risks from drinking rainwater are relatively small in the developing world context, but action is needed to ensure water safety. Water Safety Plans use an approach to manage water quality that has shown signs of success with public and communal water supplies, but relatively little research has been done to investigate the application of Water Safety Plans to self supply systems. The aim of this paper is to investigate the primary issues surrounding appropriate water quality management of domestic rainwater harvesting systems in Fiji and consider how the principles of Water Safety Plans can be applied in this context. A qualitative research design was followed, utilising semi-structured interviews with 34 rural households and six key informants, sanitary inspections of domestic rainwater harvesting systems and thematic data analysis. A number of challenges, including limited government resources and the limited knowledge and casual attitudes of rural rainwater consumers, constrain the practicality of adopting conventional Water Safety Plans at the household level, but steps for improvement can be taken.
\end{abstract}

Keywords: domestic rainwater harvesting, Fiji, water quality, Water Safety Plan

\title{
Introduction
}

Unsafe drinking-water is one of the main contributors to over one million preventable deaths of children every year (Pruss-Ustun et al. 2008). To combat this, countries around the world committed themselves to achieving Millennium Development Goal 7c to: "Halve, by 2015, the proportion of the population without sustainable access to safe drinking water and basic sanitation" (UN 2013). Access to safe drinking water is currently measured by whether or not a person has access to an "improved" drinking water source. Rainwater harvesting systems 
are such a type of "improved" water source that over 60 million people across the world primarily rely on for collecting drinking water, and it is likely that hundreds of millions more utilise rainwater as a supplementary source of water for both potable and non-potable uses (Elliott et al. 2011).

Domestic rainwater harvesting (DRWH), using the roof of a domicile as a catchment, is a common way of collecting rainwater which can then be used for a variety of domestic or productive purposes including consumption. While DRWH systems are generally considered by the WHO/UNICEF Joint Monitoring Programme to protect water from outside contamination, they have often been found in the field to have microbiological contamination levels exceeding international water quality guidelines and drinking untreated rainwater has been found to be a source of illness in the past (Kwaadsteniet et al. 2013).

In the context of the developing world, DRWH systems are likely to be just as good as other "improved" water supplies and better than "unimproved" supplies in terms of water quality (Dean \& Hunter 2012). Nevertheless, action is required to ensure the safety of rainwater during collection and storage. Good operation and maintenance of DRWH systems is one of the simplest and most effective ways to protect water quality (Gould 1999). There is a great amount of literature available on technical measures for protecting the quality of collected rainwater. However, strategies for sustainably managing water quality of self supply systems such as DRWH systems have received little attention compared to public and communal supplies (Oluwasanya et al. 2011).

Water Safety Plans (WSPs) are an approach to ensuring safe drinking-water through comprehensive risk assessment and risk management (WHO 2011). Primarily, WSPs aim to prevent contamination of water from source, through distribution to the point of consumption and to give consumers greater involvement and control over maintaining water quality (Smith \& Reed 2012). WSPs have shown signs of success when applied to public utilities 
(Gunnarsdottir et al. 2012) and communal water supplies (Mahmud et al. 2007). To date however, little research has been done to investigate the applicability of the WSP approach to self supply systems.

The aim of this paper is to investigate the primary issues surrounding appropriate water quality management of DRWH systems in Fiji, and to consider how the principles of WSPs can be applied in this context.

\section{Study location}

The Republic of Fiji (population: 874,742) is an archipelago comprising over 300 islands, approximately a third of which are inhabitated, that lies in the South Pacific Ocean about $2,100 \mathrm{~km}$ north of New Zealand. UNICEF reports that $65 \%$ of all children in Fiji have access to a metered water supply, although this figure reduces to $37 \%$ for children living in rural areas (UNICEF 2011). A combination of surface water and groundwater is often used to supply rural settlements not served by a utility, but DRWH using roof catchments remains widespread (SOPAC 2007).

\section{Methods}

A qualitative research design with cross-sectional and case study elements was used to explore the capacity, knowledge, attitudes and practices of DRWH users, and the capacity of supporting actors toward managing water quality of DRWH systems. To accomplish this, key informant interviews, household interviews and sanitary inspections of DRWH systems on-site were carried out to collect the necessary data. Household water treatment and safe storage practices are often included into WSPs, but were oustide the scope of this study. Prior to fieldwork being carried out, full ethical clearance for this research was granted by the Loughborough University Ethics Approvals (Human Participants) Sub-Committee. 


\section{Key informant interviews}

Semi-structured interviews were carried out with six key informants who were purposively selected and judged to be a sufficient sample for providing adequate insight on the study topic. Each of the key informants was a professional with expertise or specialist knowledge relating to WSPs, DRWH systems and/or government support for rural water schemes in the Pacific islands region. Guiding questions were prepared beforehand to learn about the informants' past experiences with relevant projects, and their opinions on the research topic. Interviews were recorded on a voice recorder.

\section{Household interviews}

A total of 34 households across 12 rural communities were identified, using local knowledge of where rainwater harvesting was practised, from the personal social network of the researcher. Sites were visited unannounced using a convenience sampling method. All households were located on Fiji's main island, Viti Levu. The number of sites chosen to visit was guided by advice from Perry (1998). Households within communities were selected using a snowballing method for half of the visited communities, and transect walks for the other half, in order to reduce the effects of biases inherent to each approach. A household was considered eligible if it regularly collected rainwater and an adult resident was available at the time of the visit. Semi-structured face-to-face interviews focusing on knowledge, attitudes, and practices relating to rainwater harvesting were conducted with an adult resident of each selected household. Guiding questions were prepared beforehand, translated and back-translated to ensure accuracy. Due to the nature of semi-structured interviews, questions were not strictly restricted to those previously prepared. Translators were present to perform each interview in the language the respondent preferred: English, Fijian or Fijian-Hindi. All interviews were recorded on a voice recorder.

\section{Sanitary inspections}


A sanitary inspection of the DRWH system was done after each household interview. This involved observing the cleanliness of the system and the surrounding environment, and filling out a sanitary survey form to identify the presence of potential contamination risks as decribed by WHO (2011). However, simply indicating whether or not a risk is present can underplay or exaggerate particular risk factors (Oluwasanya 2009), so the approach was modified so that risks were instead assessed on a scale of 1 to 5 . Questions on the sanitary survey were prepared by the researcher beforehand by examining generic sanitary surveys for DRWH systems found online from reputable organisations. Eleven questions were used, as shown in Table 1.

Risks were ranked using a matrix approach described by WHO (2012) for which the risks were judged, based on existing literature and the experience of the researchers, by their likelihood of happening and the severity of the consequences if they were to happen.

Although water quality analysis would have strengthened the findings of this study, it could not be included for two reasons: (1) The cost of water quality testing equipment was beyond the budget of this study, and (2) Microbiological quality of water in rainwater harvesting systems can change quickly with time. It has been suggested that to get an accurate representation, multiple test samples need to be collected over a period as long as a month (Thomas and Martinson, 2007). The timeframe of this study did not allow for repeated visits over an extended period. The authors were unable to locate any substantial local datasets for water quality of DRWH systems.

\section{Data analysis}

Quantitative data collected from sanitary inspections were entered and aggregated by question and location in an Excel spreadsheet. The data from the interviews were processed by transcribing the interviews. These data from interviews were then first analysed by a series of thematic and numeric codings where fragments of the transcriptions were placed 
into groups with common themes, or were assigned coding numbers if they were distinct enough (e.g. yes or no answers). The grouped themes were then repeatedly read and judged to make sense of their contextual meaning, to link them with each other and the quantitative data, and to relate them to the research aim. Tools such as mind mapping, hierarchical listing of themes, and quoting were also used to interpret the qualitative data.

\section{Results and discussion}

\section{Water quality risks}

\section{Sanitary inspections}

Sanitary risk questions, and aggregated sanitary survey scores for each question from the survey form, are listed in Table 1 below. It should be noted that weather conditions were mostly rainy at the times of visits, which may have improved observed roof cleanliness. 21 of the 34 households had guttering or downpipes that contained organic litter and/or retained water. No first-flush devices were observed on any systems. 18 of the 34 households had a screen between the inlet and the storage receptacle in the form of either intact fine wire mesh or cloth, while 12 of them had no form of screening or filtering. One sanitary risk question regarding the presence of visible sediment in the storage tank was omitted after it was found access hatches on tanks in the field were often tightly sealed shut. However, questions $1-3$ address the entry of physical contaminants into storage.

Table 1. A summary of sanitary risk scores from sanitary survey forms

\begin{tabular}{|c|c|c|c|c|c|c|c|c|}
\hline \multirow[t]{2}{*}{ Question } & \multicolumn{5}{|c|}{$\begin{array}{l}\text { Count of times score } \\
\text { was given } N=34, n\end{array}$} & \multirow[t]{2}{*}{ Mean } & \multirow[t]{2}{*}{$\begin{array}{l}\text { Standard } \\
\text { deviation }\end{array}$} & \multirow[t]{2}{*}{ Median } \\
\hline & 1 & 2 & 3 & 4 & 5 & & & \\
\hline $\begin{array}{l}\text { Q1. Does the roof have any visible } \\
\text { contaminants? }\end{array}$ & 30 & 4 & 0 & 0 & 0 & 1.1 & 0.3 & 1 \\
\hline $\begin{array}{l}\text { Q2. Are the guttering channels that } \\
\text { collect water dirty? }\end{array}$ & 13 & 9 & 10 & 2 & 0 & 2.0 & 1.0 & 2 \\
\hline Q3. Is there any form of screening & 18 & 3 & 0 & 1 & 12 & 2.6 & 1.9 & 1 \\
\hline
\end{tabular}


or filtering at the inlet?

Q4. Are there any other points of entry not covered?

$\begin{array}{llllll}22 & 6 & 3 & 2 & 1 & 1.6\end{array}$

Q5. Could contaminated ingress enter through faults in the storage tank?

\begin{tabular}{|c|c|c|c|c|c|c|c|c|c|c|c|c|c|c|}
\hline \multicolumn{5}{|c|}{$\begin{array}{l}\text { Q6. Are there any faeces present } \\
\text { around the collection area? }\end{array}$} & 33 & 1 & 0 & 0 & 0 & \multicolumn{2}{|c|}{1.0} & \multicolumn{2}{|c|}{0.2} & 1 \\
\hline \multicolumn{5}{|c|}{$\begin{array}{l}\text { Q7. Is the collection container kept } \\
\text { somewhere it can get contaminated? }\end{array}$} & 24 & 4 & 3 & 0 & 3 & \multicolumn{2}{|c|}{1.6} & \multicolumn{2}{|c|}{1.2} & 1 \\
\hline \multicolumn{5}{|c|}{$\begin{array}{l}\text { Q8. Is a method of diverting the } \\
\text { first flush present? }\end{array}$} & 0 & 0 & 0 & 0 & 34 & \multicolumn{2}{|c|}{5.0} & \multicolumn{2}{|c|}{0.0} & 5 \\
\hline \multicolumn{5}{|c|}{$\begin{array}{l}\text { Q9. Are there overhanging branches } \\
\text { above the catchment? }\end{array}$} & 8 & 21 & 5 & 0 & 0 & \multicolumn{2}{|c|}{1.9} & \multicolumn{2}{|c|}{0.6} & 2 \\
\hline \multicolumn{5}{|c|}{$\begin{array}{l}\text { Q10. Is the rainwater collected by } \\
\text { scooping it out? }\end{array}$} & 33 & 0 & 0 & 0 & 1 & \multicolumn{2}{|c|}{1.1} & \multicolumn{2}{|c|}{0.7} & 1 \\
\hline \multicolumn{5}{|c|}{$\begin{array}{l}\text { Q11. Does water pool under the } \\
\text { tap?* }\end{array}$} & 18 & 6 & 7 & 0 & 3 & \multicolumn{2}{|c|}{1.9} & \multicolumn{2}{|c|}{1.2} & 1 \\
\hline $\begin{array}{l}\text { Total } \\
\text { score }\end{array}$ & 16 & 17 & 18 & 19 & 20 & 21 & 22 & 23 & 24 & 25 & 26 & 27 & 28 & 29 \\
\hline $\begin{array}{l}\text { Count of } \\
\text { times total } \\
\text { score was } \\
\text { given } \\
\mathrm{N}=34, \mathrm{n}\end{array}$ & 2 & 4 & 3 & 3 & 3 & 3 & 3 & 5 & 0 & 1 & 4 & 0 & 0 & 3 \\
\hline
\end{tabular}

Note: $\quad 1=$ Risk not present or very minimal; $2-4$ : Intermediate levels of risk; $5=$ Risk poses clear threat

${ }^{*}$ Households without a tap were given a score of 1.

The sanitary survey questions above were put into six general categories and ranked in the matrix shown in Table 2. Contamination via the catchment, poorly designed gutters and uncovered openings on the storage tank were found as the greatest overall risks.

Table 2. Ranking of risks to DRWH systems studied in Fiji

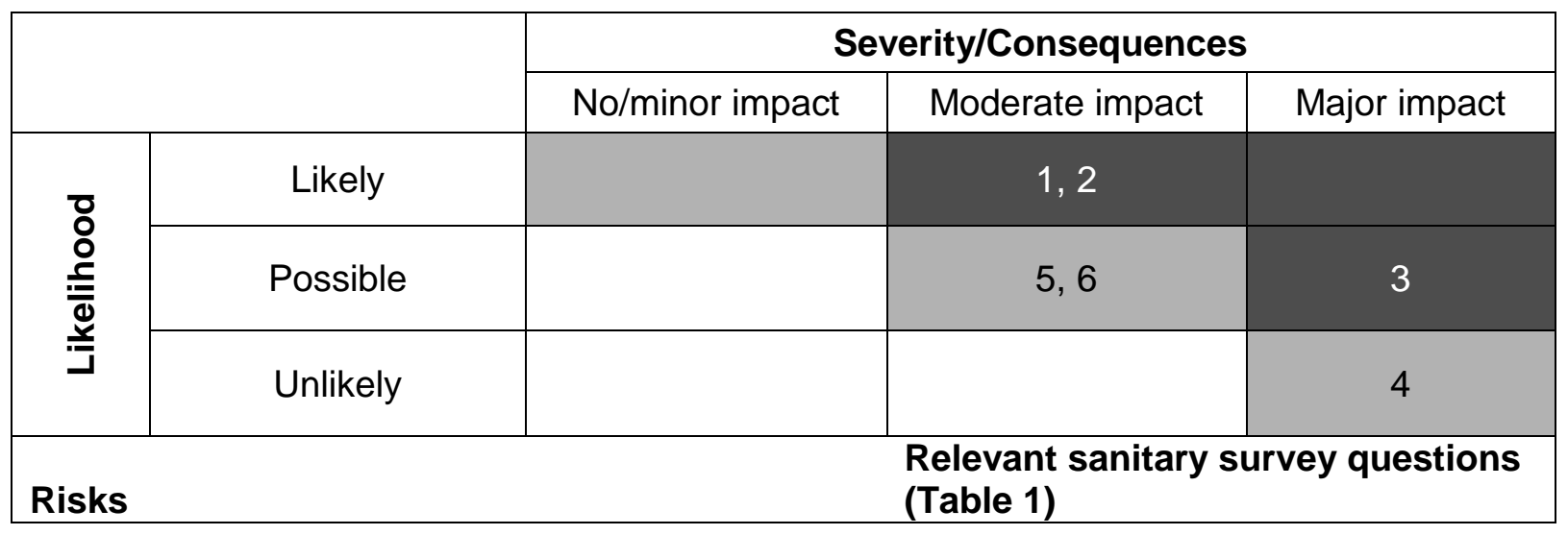




\begin{tabular}{|lc|}
\hline $\begin{array}{l}1=\text { Contamination via catchment caused by pollutants } \\
\text { transported by animals or airborne particles }\end{array}$ & Questions 1, 3, 8, 9 \\
\hline $\begin{array}{l}2=\text { Insect breeding, plant growth or pollutants deposited } \\
\text { in gutters }\end{array}$ & Questions 2, 3, 8, 9 \\
\hline $\begin{array}{l}3=\text { Direct contamination of stored rainwater through } \\
\text { uncovered openings }\end{array}$ & Question 4, 10 \\
\hline $\begin{array}{l}4=\text { Contaminated ingress entering through faults in the } \\
\text { storage tank }\end{array}$ & Question 5 \\
\hline $\begin{array}{l}5=\text { Contamination during collection from storage } \\
6=\text { Unhygienic area around collection point due to poor } \\
\text { drainage and/or faeces }\end{array}$ & Questions 6, 7, 10 \\
\hline
\end{tabular}

\section{Hazards and risks reported by users}

Respondents most frequently identified mosquito breeding and dirt/dust in storage tanks as their primary water quality concerns, which corresponds to sanitary risk questions $1-4$ in Table 1. Mosquitoes, mosquito larvae and pupae, or other physical contaminants were sometimes found in stored rainwater by users which caused them to believe that this made the water unfit for drinking without treatment. Upon discovering the presence of mosquito breeding in stored rainwater, respondents reported boiling water before drinking, throwing out the water and waiting for more rain to come, screening, settling, or using an alternative water source for drinking which was sometimes an "unimproved" or distant off-site source. Some respondents associated poor quality of collected rainwater with weather events such as wind or initial rain after dry periods: 'Sometimes when it's raining in the dry season, the water will get mosquitoes inside;' 'It's always clean except when it first rains because of the dirt on the roof;' and 'Sometimes it gets dirty because of the leaves, especially when it's windy.' No interview respondents mentioned faecal matter or microorganisms as water quality concerns.

Respondents primarily named the catchment as the pathway for physical contamination. The lack of comments made about contamination during collection and handling, direct contamination during storage through openings in the tank, and faecal matter or pathogenic microorganisms as sources of water-borne disease suggests that these householders do not have the necessary level of awareness of disease transmission to perform their own risk assessments adequately without training. A common belief that the presence of mosquito 
breeding makes water unfit for drinking sometimes had a positive outcome (treatment prior to consumption), but the decision of some respondents to turn to "unimproved" sources for drinking is a concern.

\section{Water quality management capacity}

\section{Household level}

Most respondents felt capable of regularly carrying out maintenance tasks, and recognized it as their own household's responsibility: 'We can take care of it (DRWH system) ourselves. It is our own property.' Reported maintenance tasks included screening roof run-off before it enters storage, cleaning the inside of the storage tank, cleaning guttering and downpipes, and sweeping the roof. Three respondents stated that they required help from outside their household in maintaining their systems due to their physical limitations (e.g. elderly people unable to get on the roof to periodically clean catchment and gutters). All respondents answered 'yes' when asked if it is primarily their household's responsibility in managing the quality of water of their DRWH system.

No respondents mentioned other commonly recommended preventive measures highlighted in Table 1. Respondents were also shown diagrams and given descriptions of simple DRWH technologies for improving water quality like first-flush diverters, self-cleaning inlet screens, float taps and modified inlet arrangements as shown in Abbasi and Abbasi (2011). These technologies are available and sold in Fiji, albeit not widely. None of the respondents stated they were previously aware of these components except for the inlet screen. These findings, combined with evidence discussed earlier suggesting ignorance of disease transmission routes, indicate that these DRWH users need improved education and awareness on identifying risks and ways to manage them. 
Key informants cited water testing materials being cost-prohibitive, not widely available and requiring special technical knowledge to use as barriers to household level use. Informants also stated that motivating or incentivising households to document WSP activities would be very difficult.

\section{External support}

The need for relevant institutions, primarily local government, to provide support to DRWH users in managing their systems was often stated. Raising awareness on sources of contamination and transmission routes of disease is one such need because it may currently be lacking, as one informant stated: 'I think it's understood by a lot of communities and people that rainwater is quite pure in nature. However the collection part of it and if there are possible sources of contamination, how it would influence the quality is not well understood.' Informants indicated that it is outlined in the Government of Fiji's Rural Water and Sanitation policy that all rural water supply schemes, including DRWH systems, should be tested monthly for microbiological quality, and annually for chemical quality, by local Ministry of Health officials (Fiji MoWT\&PU 2012). Further, in the context of WSPs, informants cited that DRWH users required training on risk assessment and risk management and assistance with monitoring and evaluation of WSPs.

However, resource limitations of the local government make providing these types of support at a household level challenging. According to one informant, poor accessibility to remote rural areas is an obstacle for government authorities in carrying out regular water quality testing: 'There is a problem getting local government offices access to the very remote areas. In most cases we find that the most frequent tests are carried out to communities that are much closer to the stations. It's simply because of the mobility problem they have.' Informants also noted that many DRWH users live on their own or in small settlements as opposed to traditional village settings. This creates further difficulty in accessing users to provide training or follow-up support: 
'At one time it was easy to access them because they were living in one place, but now because of economic development they are encouraged to leave their communities and move out. This is one thing that is making the issue very complicated. Because people are starting to move out, instead of going to a site and training them in one event, we have to move several times and visit each one of them. So from one community it has disintegrated into several others, they have become scattered.'

Due to these accessibility problems, government engagement with self supply water users was stated to be often only reactive; that is, water quality testing and other support only being provided when someone has become ill and the water supply is suspected to be the cause of the illness.

Government informants stated that data on how many DRWH users there are in the country and where they are located are currently incomplete. This compounds the accessibility problem because in addition to difficulty with consistently reaching users, their locations are often uncertain in the first place. It was noted by the researchers in this study that the practice of DRWH was unevenly distributed around the region where the study took place. Some informants suggested providing generic sanitary survey forms with simple instructions as described by Hasan et al. (2011). However, generic sanitary surveys may overlook risks, or cause confusion by emphasising risks that are not present in particular individual systems. One informant also pointed out that providing sanitary survey forms only for DRWH systems may cause households to fear they are dangerous, and turn to an unsafe alternative water source.

\section{Attitudes toward water quality management}


Despite concerns with physical contamination from dirt and mosquitoes, 29 out of 34 respondents stated the rainwater they collect is usually clean and safe to drink. Reasons for trusting the quality of rainwater included long-term experience with no perceived illness from drinking it (e.g. 'We have been living on it forever. Since we were born. No sickness has affected us'), belief that rainwater is inherently safe (e.g. 'Rainwater is clean because it comes from the heavens'), rainwater having good aesthetics (e.g. 'When we drink from it, it has the best taste. It is really fresh') and advice received from government health officials (e.g. 'Some people from the health department came around and explained to us that drinking from the river was bad, and that drinking rainwater is better').

When asked "Could drinking from your DRWH system ever cause illness for anyone in your family?” 20 out of $34(59 \%)$ respondents said 'no', 11 (32\%) said 'yes', and 3 (9\%) said 'I don't know'. Only one respondent believed drinking from her DRWH system had caused an illness in the past. Questions regarding how water affects health in general were not asked in this study, but a previous survey of rural households in Fiji found that most respondents identified a link between health and drinking dirty water, and believed that diarrhoea is a potentially fatal symptom (Kohlitz et al. 2013). Informants agreed that DRWH users are often aware that drinking contaminated water can have health implications. One informant summarised: 'A lot of people do actually understand what the issues are in terms of the relationship between water quality and health.'

After being shown the novel DRWH technologies previously discussed, 31 out of 34 respondents indicated that they would be interested in buying one if it was sold locally at a reasonable price (what price range was considered to be reasonable was beyond the scope of this study). Respondents were primarily interested in the technologies because of their potential to control physical contamination. One respondent commented: 'These are very good. Very good indeed because they will protect (the water) from dirt and all.' However, it should be noted that some respondents may have been answering favourably about 
willingness to purchase DRWH technologies under the belief that doing so would improve the chances of such technologies being offered to them, or because they felt it was the "right" answer to give.

These findings suggest that DRWH users in this context generally trust the quality of their collected rainwater and do not feel susceptible to infection by water-borne diseases from the rainwater which may inhibit sustainable uptake of WSP practices. An indicated willingness from respondents to purchase technologies for protecting water quality by reducing the possibility of physical contamination, combined with findings on water quality risks perceived by users, suggests that controlling physical contamination is a primary driver of water quality management in this context.

\section{Conclusions}

This study has shown that several challenges are present when trying to scale WSPs to the level of DRWH systems in the studied context. Issues of ignorance of sources and transmission routes of diseases, lack of perceived susceptibility to infection, limited knowledge of risk management options, and poor access to water quality testing resources at the household level make most DRWH users unable to prepare and implement a WSP on their own. Resource limitations, especially in terms of accessing scattered, remote DRWH users, restrict local government authorities in Fiji from providing needed levels of external support to make conventional WSPs successful. Further work is needed to assess how these challenges can be overcome to apply the WSP approach to self supply systems.

While these findings call into question the practicality of applying typical WSPs to DRWH systems in Fiji, they also provide insight on areas of water quality management that can be improved. In order to maintain safe water quality, users must understand what constitutes 
safe drinking water (Greaves \& Simmons 2011). Focused awareness-raising programmes that concentrate on how disease can be transmitted via faecal matter through a water supply, and how disease transmission can be prevented, will work to address the specific issues of ignorance and attitudes toward susceptibility to infection revealed in this study.

Control of physical contamination appears to be the primary driver of water quality management practices. Attaching messages about side-benefits, such as a reduction of dirt or mosquitoes to programmes promoting hygienic water management may help to build on existing motivating factors in this context. Further research exploring how users' practices to control physical contamination affect microbiological contamination would be useful in assessing this approach.

Sanitary surveys and risk ranking revealed contamination via the catchment, poorly designed gutters and uncovered openings on the storage tank to be the most likely to cause water quality problems among the study group. There is evidence from other studies that sending too many hygiene messages at once can overwhelm participants and waste resources during a hygiene behaviour intervention, so priority should be given to messages that are most likely to deliver the biggest health impact (Curtis et al. 2000). During education or awareness campaigns on managing DRWH systems, control measures that address the primary risks should be prioritised over less serious risks.

The scattered and remote nature of many DRWH users, and local government resource limitations, make traditional approaches for in-person support, such as community workshops and trainings, difficult. Further research on innovative methods of reaching out and providing support to DRWH users in Fiji are needed. 


\section{References}

Abbasi, T. and Abbasi, S. A. 2011 Sources of pollution in rooftop rainwater harvesting systems and their control. Critical Reviews in Environmental Science and Technology 41(23), 2097-2167.

Curtis, V., Cairncross, S. and Yonli, R. 2000 Review: Domestic hygiene and diarrhoea pinpointing the problem. Tropical Medicine \& International Health 5(1), 22-32.

Dean, J. and Hunter, P. R. 2012 Risk of gastrointestinal illness associated with the consumption of rainwater: a systematic review. Environmental Science and Technology 46, 2501-2507.

Elliott, M., Armstrong, A., Lobuglio, J. and Bartram, J. 2011 Technologies for climate change adaptation - the water sector. UNEP Risoe Centre, Roskilde.

Fiji Ministry of Works, Transport and Public Utilities - Water and Sewerage Department 2012 Fiji Rural Water and Sanitation: Practical Guidelines for Rural Water Supply Management Plan. Government of Fiji, Suva.

Gould, J. 1999 Is rainwater safe to drink? A review of recent findings. 9th International Rainwater Catchment Systems Conference. Petrolina, Brazil.

Greaves, F. and Simmons, C. 2011 Water Safety Plans for communities: Guidance for adoption of Water Safety Plans at community level. Tearfund, UK.

Gunnarsdottir, M. J., Gardarsson, S. M., Elliott, M., Sigmundsdottir, G., and Bartram, J. 2012 Benefits of water safety plans: microbiology, compliance, and public health.

Environmental Science \& Technology 46(14), 7782-9.

Hasan, T. J., Hicking, A. and David, J. 2011 Empowering rural communities: simple Water Safety Plans. Water Science \& Technology: Water Supply 11(3), 309-317.

Kohlitz, J., Hasan, T., Khatri, K., Sokota, A., Iddings, S., Bera, U. and Psutka, R. 2013 Assessing reported use and microbiological performance of a point-of-use household water filter in rural Fiji. Journal of water, sanitation and hygiene for development 3(2), 207215

Kwaadsteniet, M., Dobrowsky, P. H., Deventer, A., Khan, W. and Cloete, T. E. 2013 Domestic rainwater harvesting: microbial and chemical water quality and point-of-use treatment systems. Water Air Soil Pollut. 224(7), 1-19.

Mahmud, S.G., Shamsuddin, S.A.J., Ahmed, M.F., Davison, A., Deere, D. and Howard, G. 2007 Development and implementation of water safety plans for small water supplies in Bangladesh: benefits and lessons learned. Journal of Water and Health 5(4), 585-597.

Oluwasanya, G. 2009 Better safe than sorry: towards appropriate water safety plans for urban self supply systems. PhD Thesis, Cranfield University, UK.

Oluwasanya, G., Smith, J. and Carter, R. 2011 Self supply systems: urban dug wells in Abeokuta, Nigeria. Water Science \& Technology: Water Supply 11(2), 172-178. 
Perry, C. 1998 A structured approach for presenting theses. Australasian Marketing Journal $6(1), 63-85$.

Pruss-Ustun, A., Bos, R., Gore, F. and Bartram, J. 2008 Safer water, better health: Costs, benefits, and sustainability of interventions to protect and promote health. WHO, Geneva.

Smith, M. and Reed, B. 2012 Fact Sheet 8: An introduction to Water Safety Plans. WEDC, Loughborough.

SOPAC 2007 National integrated water resource management diagnostic report: Fiji Islands. SOPAC, Suva.

Thomas, T. and Martinson, D., 2007 Roofwater harvesting: a handbook for practitioners. IRC, Delft.

UN 2013 Goal 7: Ensure environmental sustainability [online]. Available at http://www.un.org/millenniumgoals/environ.shtml [accessed 23 September 2013]

UNICEF 2011 Children in Fiji: 2011 - An atlas of social indicators. UNICEF Pacific, Suva.

WHO 2011 Guidelines for Drinking-water Quality (4th ed.). WHO, Geneva.

WHO 2012 Water safety planning for small community water supplies: step-by-step risk management guidance for drinking-water supplies in small communities. WHO, Geneva. 